\section{Survival in COPD}

\section{S163 THE 'OBESITY PARADOX' IN CHRONIC OBSTRUCTIVE PULMONARY DISEASE}

doi:10.1136/thx.2010.150953.14

${ }^{1} \mathrm{P} F$ Collins, ${ }^{1} \mathrm{R} J$ Stratton, ${ }^{2} \mathrm{R}$ Kurukulaaratchy, ${ }^{1} \mathrm{M}$ Elia. ${ }^{1}$ Institute of Human Nutrition, School of Medicine, University of Southampton, Southampton, England, UK; ${ }^{2}$ Respiratory Medicine, Southampton University Hospital NHS Trust, Southampton, England, Uk

Poor nutritional status in chronic obstructive pulmonary disease (COPD) is associated with increased mortality independently of disease-severity (Collins et al). ${ }^{1}$ Epidemiological studies have suggested a protective role of obesity against mortality in COPD (Vestbo et al) $)^{2}$ which is contrary to data from the general population where obesity is associated with decreased life expectancy. This relationship has been referred to as the 'obesity paradox' and has been demonstrated in a number of chronic wasting conditions (Kalantar-Zadeh et al). ${ }^{3}$ This study investigated the existence of the obesity paradox in outpatients with COPD by examining the effect of body mass index (BMI) on 1-year healthcare use and clinical outcome in terms of hospital admission rates, length of hospital stay, outpatient appointments and mortality. BMI was assessed in 424 outpatients with COPD, with measurements performed by specialist respiratory nurses during outpatient clinics. 1-year healthcare use was retrospectively collected from the date of BMI measurement. Abstract S163 Table 1 Patients classified as overweight $\left(25.0-29.9 \mathrm{~kg} / \mathrm{m}^{2}\right)$ or obese $\left(>30 \mathrm{~kg} / \mathrm{m}^{2}\right)$ experienced significantly fewer emergency hospital admissions, as well as a reduced length of hospital stay, in comparison to normal weight $\left(20.0-24.9 \mathrm{~kg} / \mathrm{m}^{2}\right)$ or underweight $\left(<20 \mathrm{~kg} / \mathrm{m}^{2}\right)$ outpatients. There was a significant negative trend between BMI classification and mortality. This study supports the existence of the 'obesity paradox' in COPD, not only in relation to reduced 1 year mortality rates but also in terms of reduced emergency hospital admissions and reduced length of hospital stay.

\section{Abstract S163 Table 1}

\begin{tabular}{llllll}
\hline BMI category $\left(\mathrm{kg} / \mathrm{m}^{2}\right)$ & $<20$ & $20-24.9$ & $25-29.9$ & $>30$ \\
& $(\mathrm{n}=67)$ & $(\mathrm{n}=144)$ & $(\mathrm{n}=120)$ & $(\mathrm{n}=93)$ & $\mathrm{p}$ \\
No. EM admissions per patient & $1.5(3.7)$ & $1.2(1.7)$ & $0.74(1.4)$ & $0.71(1.1)$ & $0.011^{*}$ \\
EM LOS (days per patient) & $6.5(12.8)$ & $9.6(19.3)$ & $5.3(17.3)$ & $3.6(9.0)$ & $0.034^{*}$ \\
No. ELEC admissions per patient & $0.33(0.75)$ & $0.22(0.71)$ & $0.20(0.67)$ & $0.39(0.90)$ & $0.216^{*}$ \\
ELEC LOS (days per patient) & $1.94(7.9)$ & $0.59(2.6)$ & $0.48(3.2)$ & $2.1(13.0)$ & $0.240^{*}$ \\
OPA per patient & $3.4(2.5)$ & $4.1(3.4)$ & $3.4(2.6)$ & $3.5(2.6)$ & $0.163^{*}$ \\
1-year mortality (\%) & 21 & 15 & 5 & 4 & $<0.001 \dagger$ \\
\hline
\end{tabular}

Values are mean $\pm S D$

${ }^{*}$ ANOVA.

$\dagger X^{2}$ p-trent.

No, number; EM, emergency; ELEC, elective; LOs, length of stay; OPA, outpatient appointments.

Funding Funded by an unrestricted educational grant from Nutricia.

\section{REFERENCES}

1. Collins PF, et al. Clinical Nutrition, abstract 2010. In Press.

2. Vestbo J, et al. Am J Respir Crit Care Med 2006;173:79-83.

3. Kalantar-Zadeh K, et al. Curr Opin Clin Nutr Metab Care 2007;10:433-42.

\section{S164 \\ DIMINISHED LEFT VENTRICULAR END-DIASTOLIC DIMENSIONS PREDICT AN AMPLIFIED RISK OF DEATH IN CHRONIC OBSTRUCTIVE PULMONARY DISEASE}

doi:10.1136/thx.2010.150953.15

M Mendonca, J Brown, M Rashid, H Z Ling, S Kang, A Cheng, E Boston-griffiths, M Okorie, M Thomas, S Woldman, H Booth, Do okonko. University College London Hospital, London, UK

Background Left ventricular (LV) dimensions are markedly attenuated in chronic obstructive pulmonary disease (COPD) possibly due

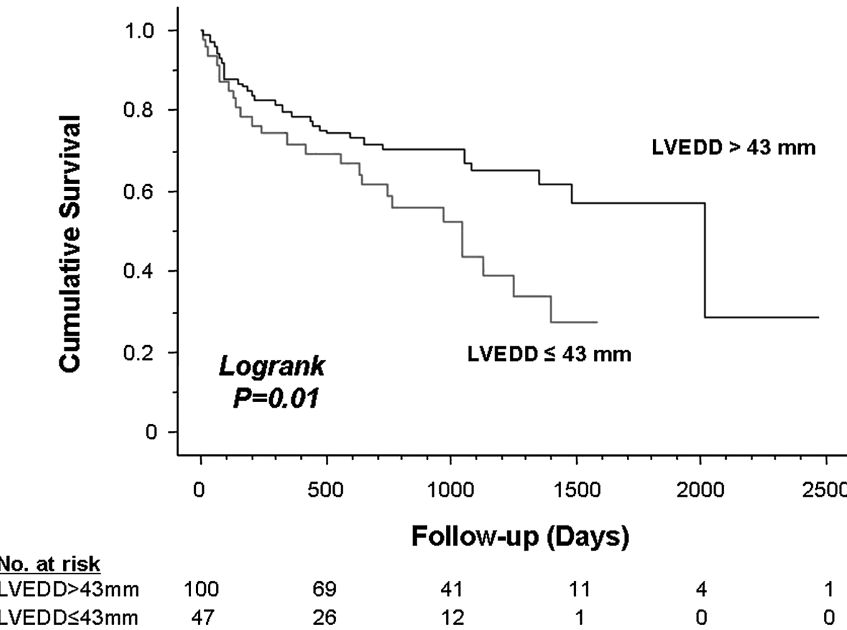

Abstract S164 Figure 1

to impairments in LV filling that result from increased pulmonary vascular resistance, ventricular interdependence, diastolic dysfunction or incessant tachycardia. Whether reductions in LV size carry adverse prognostic implications in this cohort is unclear.

Methods We analysed the relation between echocardiographic indices and mortality in $147 \mathrm{COPD}$ patients (mean [ $\pm \mathrm{SD}$ ] age $76 \pm 10$ years, forced expiratory volume in $1 \mathrm{~s}$ [FEV1] $0.85 \pm 0.341$, forced vital capacity [FVC] $1.44 \pm 0.601$, FEV1/FVC 0.62 \pm 0.16 , LV ejection fraction [LVEF] $56 \pm 12 \%$ ) with homogenous right ventricular $(42 \pm 14 \mathrm{~mm} \mathrm{Hg})$ and pulmonary arterial systolic $(45 \pm 17 \mathrm{~mm}$ $\mathrm{Hg})$ pressures.

Results Decreased LV end-diastolic (LVEDD $\leq 37 \mathrm{~mm}$ ) and endsystolic (LVESD $\leq 25 \mathrm{~mm}$ ) diameters, ejection fraction $(<45 \%)$, and diastolic function (E/A ratio $<1$ or $>2$ ) were evident in $10 \%, 14 \%$, $18 \%$ and $71 \%$ of patients, respectively. Lower LVEDDs correlated significantly to lower LVESDs $(r=0.83)$, higher LVEFs $(r=-0.54)$, lower FEV1s $(r=0.29)$, and lower FVCs $(r=0.20)$ but not to age, right ventricular systolic pressures or pulmonary arterial pressures. Over a mean follow-up of $26 \pm 18$ months, 60 (41\%) patients died. Only a lower LVEDD predicted increased mortality $\left(c^{2} 4.4, p=0.03\right)$ with each $1 \mathrm{~mm}$ decrement in LVEDD conferring a $3 \%$ escalated risk of death. An LVEDD $\leq 43 \mathrm{~mm}$ optimally predicted mortality and was associated with an $89 \%$ reduction in survival compared to an LVEDD $>43 \mathrm{~mm}$ (Abstract S164 Figure 1). No variable affected the prognostic impact of LVEDDs in adjusted analyses.

Conclusions Attenuations in left ventricular end-diastolic diameter forecast an enhanced risk of death in patients with COPD, irrespective of lung function and pulmonary arterial pressures. Improving LV filing and dimensions in this cohort may augment survival.

\section{S165 DEPRIVATION IS AN INDEPENDENT PREDICTOR OF 1-YEAR MORTALITY IN OUTPATIENTS WITH CHRONIC OBSTRUCTIVE PULMONARY DISEASE}

doi:10.1136/thx.2010.150953.16

${ }^{1} \mathrm{P} F$ Collins, ${ }^{1} \mathrm{R}$ J Stratton, ${ }^{2} \mathrm{R}$ Kurukulaaratchy, ${ }^{1} \mathrm{M}$ Elia. ${ }^{1}$ Institute of Human Nutrition, School of Medicine, University of Southampton, Southampton, England, UK; ${ }^{2}$ Respiratory Medicine, Southampton University Hospital NHS Trust, Southampton, England, UK

Deprivation is linked to increased incidence in a number of chronic diseases but its relationship to chronic obstructive pulmonary disease (COPD) is uncertain despite suggestions that the socioeconomic gradient seen in COPD is as great, if not greater, than any 
other disease (Prescott and Vestbo). ${ }^{1}$ There is also a need to take into account the confounding effects of malnutrition which have been shown to be independently linked to increased mortality (Collins et al). ${ }^{2}$ The current study investigated the influence of social deprivation on 1-year survival rates in COPD outpatients, independently of malnutrition. 424 outpatients with COPD were routinely screened for malnutrition risk using the "Malnutrition Universal Screening Tool'; 'MUST' (Elia), ${ }^{3}$ between July and May 2009; 222 males and 202 females; mean age 73 (SD 9.9) years; body mass index 25.8 (SD 6.3) kg/m². Each individual's deprivation was calculated using the index of multiple deprivation (IMD) which was established according to the geographical location of each patient's address (postcode). IMD includes a number of indicators covering economic, housing and social issues (eg, health, education and employment) into a single deprivation score (Nobel et al). ${ }^{4}$ The lower the IMD score, the lower an individual's deprivation. The IMD was assigned to each outpatient at the time of screening and related to1-year mortality from the date screened. Outpatients who died within 1-year of screening were significantly more likely to reside within a deprived postcode (IMD 19.7 \pm SD 13.1 vs $15.4 \pm$ SD 10.7; $p=0.023$, OR $1.03,95 \%$ CI 1.00 to 1.06 ) than those that did not die. Deprivation remained a significant independent risk factor for 1year mortality even when adjusted for malnutrition as well as age, gender and disease severity (binary logistic regression; $p=0.008$, OR $1.04,95 \%$ CI 1.04 to 1.07). Deprivation was not associated with disease-severity $(p=0.906)$ or body mass index, $\mathrm{kg} / \mathrm{m}^{2} \quad(p=0.921)$ using ANOVA. This is the first study to show that deprivation, assessed using IMD, is associated with increased 1-year mortality in outpatients with COPD independently of malnutrition, age and disease severity. Deprivation should be considered in the targeted management of these patients.

Funding Funded by an unrestricted educational grant from Nutricia.

\section{REFERENCES}

1. Prescott, Vestbo. Thorax 1999:54:737-41.

2. Collins PF, et al. Clinical Nutrition, abstract 2010. In Press.

3. Elia M, ed. The 'MUST' report. BAPEN, Redditch 2003. http://www.bapen.org.uk.

4. Nobel, et al. The English indices of deprivation 2007. 2008. http://www.communities. gov.uk.

\section{S166 THE ROLE OF CLINICAL, METABOLIC AND CARDIAC BIOMARKERS IN PREDICTING OUTCOME FROM COPD EXACERBATIONS REQUIRING HOSPITAL ADMISSION: A PROSPECTIVE OBSERVATIONAL STUDY}

doi:10.1136/thx.2010.150953.17

${ }^{1} \mathrm{G}$ Tack, ${ }^{1} \mathrm{~V}$ Osman-Hicks, ${ }^{1} \mathrm{~A}$ Hicks, ${ }^{2} \mathrm{Y}$ Perry, ${ }^{1} \mathrm{R} \mathrm{M}$ Angus, ${ }^{3} \mathrm{P} \mathrm{M}$ A Calverley, ${ }^{1} \mathrm{~B}$ Chakrabarti. ${ }^{1}$ Aintree Chest Centre, University Hospital Aintree, Liverpool, UK; ${ }^{2}$ Department of Biochemistry, University Hospital Aintree, Liverpool, UK; ${ }^{3}$ Clinical Sciences Centre, University of Liverpool, Liverpool, UK

Introduction Baseline hyperglycaemia along with Respiratory Rate has been shown to represent a marker for mortality and failure of Non Invasive Ventilation in COPD exacerbations complicated by decompensated respiratory failure. This study aims to determine whether the same association holds true for those COPD exacerbations admitted to hospital in the absence of respiratory acidosis and if other markers may predict outcomes in such a population.

Methodology COPD patients admitted to University Hospital Aintree with an acute exacerbation were recruited within $48 \mathrm{~h}$ of admission with the primary end point being 3 month mortality. Patients presenting with respiratory acidosis were excluded. Subjects underwent clinical assessment at recruitment; blood samples were drawn for Random Blood glucose (RBG), Brain Natriuretic Peptide
(BNP) level (Siemens Healthcare@). Admission ECGs were analysed in order to calculate Cardiac Infarction Injury Score (CIIS).

Results 116 patients (mean age 70 years; 55\% female; FEV1 0.98 (predicted 2.49) litres; admission ABGS pH 7.40; PCO2 5.93kPA; PO2 9.04kPA) were recruited; $18(16 \%)$ patients had died by 3 months. Hyperglycaemia (defined as $\mathrm{RBG} \geq 7 \mathrm{mmol} / \mathrm{l}$ ) was not associated with increased 3 month mortality (observed in $6 / 18$ (33\%) of deaths at 3 months vs $35 / 98(36 \%)$ of survivors; $p=0.85$ ). The Respiratory Rate (RR) measured during clinical assessment appeared to significantly higher in those who had died by 3 months (27 (SD 5) vs 24 (SD 5); $\mathrm{p}=0.048$ ). No association was observed between those who had died by 3 months in terms of BNP levels (18.71 vs $24.22 \mathrm{pg} / \mathrm{ml} ; \mathrm{p}=0.48$ ), CIIS (7.65 vs $6.25 ; \mathrm{p}=0.37$ ), age (71 vs 70 years; $\mathrm{p}=0.63), \mathrm{PaCO} 2$ (6.29 vs $5.87 \mathrm{kPA}$ ) or serum Bicarbonate (25 vs $26 \mathrm{mmol} / \mathrm{l} ; \mathrm{p}=0.64$ ). An inverse correlation was noted between $\mathrm{BNP}$ values and admission PaCO2 levels (Correlation coefficient $-0.25 ; \mathrm{p}=0.018$ ) and Bicarbonate levels (Correlation coefficient $-0.35 ; \mathrm{p}=0.001)$; a positive correlation was observed between BNP levels and patient age (Correlation coefficient -0.35 ; $\mathrm{p}=0.002$ ).

Discussion In patients admitted to hospital with COPD exacerbations, hyperglycaemia, BNP level and CIIS were not found to be predictors of mortality in the absence of acute respiratory acidosis. Interestingly, Respiratory Rate measured whilst in hospital appears to predict outcome at 3 months.

\section{S167 EXPANSION OF THE RED CELL DISTRIBUTION WIDTH AND EVOLVING IRON DEFICIENCY AS PREDICTORS OF POOR OUTCOME IN CHRONIC OBSTRUCTIVE PULMONARY DISEASE}

doi:10.1136/thx.2010.150953.18

M Rashid, J Brown, H Z Ling, M Mendonca, S Kang, R Sofat, M Okorie, M Thomas, S Woldman, H Booth, Do okonko. University College London Hospital, London, UK

Background Chronic obstructive pulmonary disease (COPD) is a multi-system disorder driven partly by diffuse inflammation, malnutrition and haematological aberrations. Because the red blood cell distribution width (RDW) is a surrogate of these anomalies, we hypothesised that it might be of prognostic importance in COPD patients. Additionally, we tested the supposition that iron deficiency (ID) per se could be a prevalent and ominous co-morbidity in these individuals.

Methods We analysed the relation of red cell indices on admission and over time with mortality in 655 consecutively eligible COPD patients (mean $\pm \mathrm{SD}$ age $77 \pm 12 \mathrm{y}$, FEV1 $0.85 \pm 0.34 \mathrm{l}$, FVC $1.44 \pm 0.601,54 \%$ male). Concomitant heart failure, ischaemic heart disease, and neoplasia were exclusion criteria. The combination of a high RDW and low mean cell haemoglobin $(\mathrm{MCH})$ was utilised to identify ID

Results On admission, an $\mathrm{RDW}>15 \%, \mathrm{Hb}<12.5 \mathrm{~g} / \mathrm{dl}, \mathrm{MCH}<27$, and ID were evident in $33 \%, 31 \%, 12 \%$ and $10 \%$ of patients. Compared to those with an RDW $\leq 15 \%$, patients with levels $>15 \%$ had lower Hbs, lower FEV1s, and longer median ( \pm IOR) hospital stays $(9 \pm 11$ vs $8 \pm 8$ days, $\mathrm{P}<0.001)$. Over a mean period of $40 \pm 29$ months, 227 (35\%) patients died. On Cox proportional hazards analyses, a higher RDW predicted increased mortality (adjusted $\chi^{2}$ $16, \mathrm{P}<0.0001)$ independently of age $\left(\chi^{2} 11, \mathrm{P}<0.001\right)$, FEV1 $\left(\chi^{2} 5\right.$, $\mathrm{P}<0.03), \mathrm{Hb}$ and creatinine (latter two not retained in model) and provided graded prognostic information (abstract S167 figure 1A) incremental to that of FEV1 $\left(\mathrm{P}<0.05\right.$ for change in $\left.\chi^{2}\right)$. Over time, $63 \%, 72 \%, 65 \%$, and $46 \%$ of patients had a rise in $\mathrm{RDW}$, a fall in $\mathrm{Hb}$, a fall in $\mathrm{MCH}$, and evolving ID (rising RDW and falling $\mathrm{MCH}$ ), respectively. A rising RDW predicted death (adjusted $\chi^{2} 32$ $\mathrm{P}<0.0001$ ) independently of baseline RDWs and changes in $\mathrm{Hb}$, 